\title{
PRESENTACIÓN: PENSAMIENTO ECONÓMICO DE LA ESCUELA DE SALAMANCA. ANTECEDENTES Y RECEPCIÓN
}

\author{
PRESENTATION: ECONOMIC THOUGHT OF THE SCHOOL OF \\ SALAMANCA. BACKGROUND AND RECEPTION
}

\author{
VIRGINIA ASPE \\ Universidad Panamericana, México \\ MAURICIO LECÓN \\ Universidad Panamericana, México
}

El presente volumen de la revista Cauriensia está dedicado al pensamiento económico de la Escuela de Salamanca. En él reunimos once investigaciones, a cargo de catorce autores en total -diez hombres y cuatro mujeres- de distintas nacionalidades y pertenecientes a diversas universidades públicas y privadas. Desde principios del siglo pasado, los estudios especializados sobre el pensamiento económico de los autores salmantinos han aumentado exponencialmente. Hasta el punto en que, actualmente, no sólo gozamos de un vasto acervo bibliográfico sobre la materia, sino de trabajos altamente sofisticados que han contribuido a la recuperación, evaluación y análisis críticos de sus principales ideas. Aunque el estado de la cuestión es favorable, dista mucho de ser definitivo o, siquiera, comparable con los avances alcanzados en otras áreas de la filosofía y la economía.

Estamos convencidos de que, en lo individual y en lo colectivo, este monográfico es una valiosa aportación a esa tarea pendiente; entre otras razones, porque tiene tres grandes cualidades. En primer lugar, el volumen atiende a las influencias, el desarrollo y la recepción de algunas ideas o problemas discutidos por los autores de la Escuela. La visión panorámica y ordenada que colectivamente construyen estos trabajos no sólo permite situar a los autores salmantinos 
en la tradición filosófica y económica, sino que también captura el dinamismo contextual de la Escuela; es decir, revisa los antecedentes y recepción de las ideas económicas posibilitando así lecturas o interpretaciones más robustas sobre sus integrantes. En segundo lugar, el volumen se compone de once aproximaciones originales a problemas típicos sobre las ideas económicas salmantinas. Dicha originalidad resulta de las diferentes áreas de especialización desde las cuales proceden los autores: algunos expertos en filosofía antigua, otros en filosofía medieval, renacentista o, incluso moderna. Esta diversidad dota al número de una frescura que se ve reflejada en los temas, ángulos y métodos para abordar problemas típicos en estos autores. Por último, destacamos que el volumen supera algunos vicios en los que ha incurrido la literatura especializada; a saber, el tono apologético y la regionalización de los estudios. Ante la prolongada omisión y desconocimiento de la Escuela de Salamanca en la historia la filosofía y de la economía, ${ }^{1}$ los primeros estudiosos emprendieron la reconstrucción de ideas y decididamente adoptaron un tono Reivindicatorio con los distintos autores. Con el paso del tiempo, estos esfuerzos maduraron dando lugar a trabajos que abandonaron el abordaje expositivo de decir quién es el autor, describir su producción, contexto y las generalidades de su pensamiento para, en cambio, realizar análisis moderados y sofisticados con herramientas filológicas, históricas y documentales. En sintonía con esta evolución, varios trabajos del presente número asumen una posición crítica hacia los autores salmantinos y hacia sus ideas; lo cual ayuda a ponderar mejor sus aportaciones y reparar en sus limitaciones o defectos. Adicionalmente, la alta participación de académicos latinoamericanos confirma a la Escuela de Salamanca como un objeto de interés general para la academia y no sólo para hispanistas o libertarios -quienes rehabilitaron el pensamiento económico salmantino por su aparente simpatía con la Escuela Austríaca-.$^{2}$ Puede decirse, entonces, que estamos ante planteamientos más aporéticos cuyo valor está en las preguntas que despiertan y en la interpretación contextual que hacen de las fuentes salmantinas. Así las cosas, el volumen goza de una unidad orgánica en la que una diversidad de enfoques e inquietudes convergen en una narrativa histórica y temática.

Nuestro volumen comienza con un par de trabajos que revisan dos antecedentes fundamentales de los autores salmantinos: Tomás de Aquino y Duns

1 Véase Weber, Max, La ética protestante y el espíritu del capitalismo (Madrid: Akal, Istmo, 2013); Luigi Cossa, An Introduction to the Study of Political Economy (London, 1893), 141.

2 Véase: De Roover, Raymond, "Scholastic Economics: Survival and Lasting Influence from the Sixteenth Century to Adam Smith", Quarterly Journal of Economics 69 (mayo 1955): 161-190; Grice-Hutchinson, Marjorie, "The Salamanca School. Readings in Spanish Monetary Theory 15441605" (Oxford: Oxford University Press, 1952); Schumpeter, Joseph A., History of Economic Analysis (London: Routledge, 1969). 
Escoto. El Aquinate fue una fuente expresamente asumida por la gran mayoría de los teólogos de Salamanca; por el contrario, Escoto solía ser referido con cierto antagonismo. Héctor Zagal inaugura el volumen con su análisis del tema de la usura en Tomás de Aquino. Articula su texto a partir de la revisión crítica del mismo concepto. Con base en el De malo, el Comentario a la Política y, particularmente, en la $q$. 78, de la II-IIa de la Suma teológica de Tomás, Zagal repara en la ontología del dinero y en su carácter potencial. Dicha condición del dinero implica, entre otras cosas, que no tiene un valor en sí mismo, sino sólo aquél que le es dado por el trabajo de los agentes. La naturaleza del dinero supone que éste es un mero instrumento para facilitar ciertas transacciones comerciales. Así las cosas, Zagal pone de relieve que el aristotelismo de Tomás se asoma en su condena contra el cobro de interés en los préstamos monetarios por su carencia de un término medio, lo que hace de dicha práctica una acción intrínsecamente mala.

Por su parte, Mauricio Lecón pasa revista a las críticas que algunos profesores de Salamanca dirigieron contra Duns Escoto. Los teólogos salmantinos reconocieron que las dos únicas fuentes para la determinación del precio de un bien son la autoridad y la estimación común. Domingo de Soto, Luis de Molina y Juan de Lugo criticaron al Doctor Sutil por haber afirmado que el justo precio, además, debía computar el riesgo y el trabajo del vendedor. Lecón argumenta que la crítica es improcedente porque es una interpretación parcial y simplista de las fuentes escotistas. Dicha improcedencia se extiende a las opiniones de estudiosos contemporáneos, quienes describen a Escoto como un defensor de una teoría objetivista del valor apoyándose en las fuentes salmantinas. Lecón logra mostrar que la opinión de Escoto acerca del precio justo es más cercana a las tesis de los autores salmantinos de lo que ellos mismos y los especialistas reconocen. Lo cual arroja un halo de originalidad sobre Escoto o, bien, añade una nota más tradicional a las ideas de la Escuela.

Los trabajos sucesivos del volumen están dedicados a discusiones concentradas en los autores salmantinos. El trabajo "Pobreza, trabajo y comunidad en Vasco de Quiroga", de las autoras Cecilia Sabido y María Tedesco conecta el humanismo de Vasco con el humanismo cívico de los catedráticos del siglo XV en la Universidad de Salamanca. Para ello, Sabido y Tedesco escudriñan la noción de pobreza de Quiroga a la luz de algunas ideas de la época, como el pensamiento de Luis Vives. Esto con la intención de destacar la importancia que Vasco de Quiroga da al trabajo y a la comunidad de bienes como mecanismos de perfeccionamiento humano. Lo cual, las autoras sugieren, indudablemente influyó en el pensamiento utópico de Tomás Moro. 
A su vez, en su trabajo "Sobre avaricia y lujo de encomenderos en el Octavo remedio de Bartolomé de Las Casas", Virginia Aspe discute el tema de la economía a la luz de la avaricia, la codicia y el lujo en los encomenderos novohispanos del siglo XVI. Aspe propone que el criterio lascasiano de aproximación al problema se da a la luz de la ley natural de la I-IIae, q. 90-94 de la S. Th., y que el dominico se ampara en el pacto fundacional de las Leyes de Castilla para rechazar los usos excesivos del dinero. La autora prueba que el discurso lascasiano se hace más radical que el de la Escuela de Salamanca en la medida en que conecta la práctica de la usura con pasajes del Antiguo Testamento, pasajes en los que la desposesión de grupos vulnerables es considerada más perversa por la exclusión que implica de las necesidades básicas de sus gentes. Con esta precisión la autora da cuenta de la conexión entre Bartolomé de las Casas y los movimientos emancipatorios indigenistas del siglo XX.

El texto "Derecho subjetivo, naturaleza y dominio en Francisco de Vitoria" de Luis Cendejas desentraña las distintas tradiciones que influyeron en la noción de dominio y derecho en Francisco de Vitoria. En estos tiempos en que hay una sobrevaloración de la contribución árabe sobre el pensamiento de Tomás de Aquino, Cendejas nos recuerda que fueron el derecho romano y el nominalismo las tradiciones que permitieron que Vitoria formulase su noción subjetiva del derecho, la cual, no conduce a un voluntarismo jurídico ni político por su fuerte vinculación a la ley natural, fuente de dichos derechos. Cendejas sostiene que también el estoicismo contribuyó a la teoría medieval vitoriana del origen de las instituciones. Las dos contribuciones originales de esta investigación son: señalar la impronta estoica en estas nociones, que generalmente se olvida en el pensamiento medieval, y rescatar una noción medieval de derecho subjetivo que libra los inconvenientes voluntaristas por su raigambre tomista.

En su trabajo, "Riqueza y cultura económica en la España del siglo XVI. La predicación de Tomás de Villanueva en tiempos de Francisco de Vitoria", Clemente López y José Ignacio Ruiz hacen eco de un motivo tratado anteriormente: la avaricia. Su aproximación tiene el atractivo de que es hecha desde los sermones de san Tomás de Villanueva. Los cuales, por su finalidad persuasiva y correctiva, ayudan a retratar la mentalidad y cultura económica cotidiana de la época. El análisis y exposición de los discursos revela las condenas de Villanueva contra la codicia, usura y avidez desmedida en ricos y burgueses que intentan ascender en la escala social. Sin embargo, el tratamiento crítico de las fuentes ayuda a manifestar opiniones más teóricas acerca la naturaleza de la riqueza, la especificidad de la moral económica, la finalidad de uso del dinero y las consecuencias de su mal empleo. Así, Cendejas y Ruiz logran dibujar la sensibilidad económica de un momento histórico desde las palabras moralizantes 
de un autor, las cuales sirvieron para que la sociedad tomara conciencia de las necesidades de los grupos menos protegidos fomentando estrategias económicas de beneficencia.

En “Tomás de Mercado y la transfretación de bienes y normas", José Luis Egío analiza el soslayado tema del probabilismo que la literatura salmantina había olvidado hasta que recientes estudios monográficos retomaron el tema. Egío parte de la renovación que Tomás de Mercado hizo del probabilismo en ocasión de la necesidad de aplicar nuevos métodos para la teología moral de su época. Nos dice el autor que, pese a que en Mercado estas tesis carecen aún de un planteamiento sistemático, la Suma de tratos y contratos incorpora el planteamiento probabilista de cara a las incertidumbres creadas por los descubrimientos de ultramar y la economía que se produjo. El autor parte del probabilismo de Azpilicueta para argumentar que el Doctor Navarro aún se mantenía en la vieja enseñanza medieval de optar siempre por la opción más segura para la salvación; pero señala que en Tomás de Mercado ya existe una metodología específica para discernir entre varias argumentaciones probables que impregnan la literatura moral de las actividades económicas. Sostiene que la Suma de tratos y contratos es una de las primeras respuestas filosófico-morales en la que los bienes, las prácticas y las normas son objeto de transfretación. Egío argumenta que Tomás de Mercado es el primero para quien el probabilismo no es aislado ni casual, sino que hace las veces de bóveda en el laberinto de las acciones. Como el descubrimiento de América implicó una transformación en la cultura social y económica, el texto sugiere que hay una innovación sin precedentes en la práctica de tratos y contratos ya no como práctica consuetudinaria. La aportación del texto es la consideración mercadiana del probabilismo por la complejidad e incerteza de los nuevos temas mercantiles, probando que éste no solo fue obra de Bartolomé de Medina como técnica para dirimir problemas de conciencia. El texto prueba, una vez más, que las tesis de Weber en torno al rechazo del catolicismo para transitar a la modernidad son falaces.

Gabriela Caram aborda el pensamiento económico de Martín Azpilicueta como uno de los fundadores de la economía científica en "Martín de Azpilicueta: aportes económicos y su influencia en teorías económicas posteriores". La autora defiende que Azpilicueta supo integrar el desarrollo económico analítico con el ético-normativo en ocasión del comercio y crédito de su tiempo. Además, demuestra el impacto de sus teorías en desarrollos ulteriores. El texto es una contribución original al abordar en enfoque canonista y no sólo teológico y de derecho positivo en su Comentario resolutivo de cambios, donde acepta las ganancias sin considerarlas usura siempre y cuando sean moderadas. El principio del que parte Azpilicueta es el de la equivalencia en razón de lo entregado y 
lo recibido para mantener la proporción debida entre las partes. Caram da seguimiento al Manual de confesores e penitentes de 1556, obra que se considera la primera teoría cuantitativa del dinero. Una particularidad en la autora es su lectura de los textos económicos de Azpilicueta a la luz del De Regimine principum, 14 de Tomás de Aquino, y no desde los pasajes relativos a la usura en la Suma teológica. Sostiene que la teoría cuantitativa del dinero de Azpilicueta en el Comentario resolutivo de cambios es la primera formulación del valor cuantitativo del dinero y considera al autor navarro el antecedente del liberalismo económico moderno.

El resto de colaboraciones del volumen atienden al impacto que las ideas económicas de los autores salmantinos tuvieron. Uno de ellos se concentra en la figura de Francisco Suárez y su aristotelismo. Otro desarrolla la manera en que las ideas de los salmantinos forjaron la opinión de Leibniz acerca de la moralidad de los seguros. El último artículo, en cambio, es un análisis cuantitativo que ayuda a destilar algunas inferencias sobre la Escuela de Salamanca apoyándose en el trabajo y compendio de uno de los mayores especialistas en el tema, José Barrientos. En "Restitución y justicia correctiva en la tradición aristotélico-escolástica: la contribución de Francisco Suárez (1548-1617)", Sebastián Contreras distingue el valor de la restitución de la teoría jurídica clásica frente a la restitución de la teoría aristotélico-escolástica de justicia correctiva en la Escuela de Salamanca. El autor considera que la primera atiende exclusivamente al aspecto reparatorio de la injusticia, mientras que la tradición aristotélica de la Escuela de Salamanca considera otros importantes fines en la valoración del acto justo cara a la restitución. Contreras analiza esta contribución de fines a la luz de la teoría suareciana de la justicia correctiva demostrando que Suárez tiene una función instituyente y directiva de las conmutaciones que excede el ámbito de la reparación. La investigación parte del vicio excesivo por la riqueza -la usura-, causa de todos los males económicos que van contra la justicia y yerran contra la equidad, virtud y proporción, cayendo en abusos. El texto analiza el punto a la luz del significado griego de la plexonia, en una aproximación robusta que avanza sobre el enfoque tradicional sobre Suárez, para probar que es desde Aristóteles más que desde la tradición medieval que la ganancia acompañada del bien común implica la completud recta del deseo. Concluye que, para Suárez, basado en la noción aristotélica de synallágmata, la reparación no agota el orden funcional de la justicia correctiva. Si la restitución es un tipo de especie de pago de lo debido, cualquier restitución supone que el orden de la justicia que existía con anterioridad se reestablezca, y de acuerdo con esto, esferas como el honor y la integridad deben también ser contempladas. 
Por su parte, la sugerente entrega de Leonardo Ruiz explora las raíces salmantinas de la opinión de Leibniz acerca de la moralidad de los seguros. La propuesta leibniziana se reduce a convertir las instituciones aseguradoras en instituciones públicas. De esta manera, ningún particular lucra con el riesgo - evitando así la usura- ni hace negocio con asuntos de la Providencia. El autor realiza una cuidadosa exégesis para revelar las voces escolásticas que subyacen a la posición de Leibniz. La falta de referencias o menciones a las fuentes medievales no son un signo de lo contrario. Antes bien, es un fenómeno comprensible dado el tipo de textos de Leibniz y del público al que iban dirigidos, pues al discutir los seguros en documentos diplomáticos que pretendían persuadir a católicos y protestantes por igual, era razonable no invocar autoridades de ninguna rama religiosa. En cualquier caso, Leonardo Ruiz logra incorporar a Leibniz a la tradición económica salmantina como un caso importante de recepción.

El último trabajo de este volumen, el de Germán Scalzo y Antonio Moreno Almárcegui, es un auténtico corolario a los estudios previos. Los autores avanzan en el revisionismo de fuentes que analizan la economía en la Escuela de Salamanca. Los autores defienden que el repertorio de fuentes presentadas por Barrientos (Repertorio de moral económica (1526-1670). La Escuela de Salamanca y su proyección. EUNSA, 2011), es el intento de configurar un pensamiento sistemático y especializado de los problemas económicos del siglo XVI. Con herramientas cuantitativas, Scalzo y Moreno muestran la relevancia de los distintos autores sobre el tema y su crecimiento en el siglo XVI y revisan su relación con las distintas ediciones y órdenes. Como resultado, se muestra la presencia preponderante de la Compañía de Jesús en la Escuela de Salamanca a partir de 1593 y se rastrea el número de citas a Tomás de Aquino y a otras influencias para comprender bien la evolución de la Escuela por referencias a las Sagradas Escrituras, la patrística, el magisterio, el derecho romano y otras vías de interpretación, como la vía franciscana, etc. Por último, el texto hace un análisis temático mostrando la frecuencia de términos utilizados dando los 95 índices de obras publicadas y los 57 conceptos usados en el mundo mercantil, probando con esto el eco que tuvo la Escuela en Europa entre 1590 y 1640. Todo lo anterior ayuda esclarecer el concepto de Escuela de Salamanca explicitando algunas tendencias, influencias e intereses de sus miembros.

Agradecemos al editor en jefe de Cauriensia, Manuel Lázaro Pulido, la confianza que depositó en el grupo de académicos e investigadores -todos miembros del Consejo Nacional de Ciencia y Tecnología en México y equivalentes en otros países- que colaboran en este volumen. Damos las gracias, también, a la Facultad de Filosofía de la Universidad Panamericana por su apoyo, así como a Ana M. Landeta, Roberto Molina y Esteban Soní por ayudar en la 
edición. Esperamos volver a colaborar en el futuro con cada uno de Ustedes y continuar con este esfuerzo de profundización en las aportaciones económicas de la Escuela de Salamanca.

\author{
Virginia Aspe \\ Facultad de Filosofía \\ Universidad Panamericana \\ Augusto Rodin 498, Insurgentes Mixcoac \\ 03920 Ciudad de México (México) \\ https://orcid.org/0000-0002-0685-7721 \\ Mauricio Lecón \\ Facultad de Filosofía \\ Universidad Panamericana \\ Augusto Rodin 498, Insurgentes Mixcoac \\ 03920 Ciudad de México (México) \\ https://orcid.org/0000-0002-9928-7739
}

